\title{
Bullying Analysis in SDN Pandean Lamper 02 Kota Semarang
}

\section{Anggun Dwi Setya Putri, Muhammad Arief Budiman}

\author{
Universitas PGRI Semarang \\ anjuuundsp@gmail.com
}

\section{Article History}

accepted 24/09/2019

\begin{abstract}
The most common causes of bullying at school come from peers or classmates and seniors. Bullying is one of the many phenomena that occur in this millennial era. Many school children are victims and also the main perpetrators of bullying cases. Therefore, the purpose of this research is to analyze bullying at SDN Pandean Lamper 02 Semarang City. This study uses descriptive qualitative methods, with data collection techniques using interviews, observation, and documentation. The research subjects were students who were perpetrators or victims of bullying, principals, and teachers. Based on research, the results obtained that bullying behavior occurs in the form of physical bullying and verbal bullying. Physical bullying involves hitting, pushing, forcing, damaging, pinching, kicking, nudging, pulling clothes and pulling hairs. Verbal bullying consists of yelling, cheering, talking dirty, mocking and calling with certain nicknames.
\end{abstract}

Keywords: bullying behavior, forms of bullying, students

\section{Abstrak}

Penyebab terjadinya bullying di sekolah kebanyakan datang dari teman sebaya atau kakak kelas. Bullying menjadi salah satu fenomena yang banyak sekali terjadi di era milenial ini. Banyak anak sekolah yang menjadi korban dan juga pelaku utama kasus bullying. Oleh karena itu, tujuan dalam penelitian ini yakni menganalisis bullying di SDN Pandean Lamper 02 Kota Semarang. Penelitian ini menggunakan metode deskriptif kualitatif, dengan teknik pengumpulan data menggunakan wawancara, observasi, dan dokumentasi. Subjek penelitian adalah siswa pelaku atau korban bullying, kepala sekolah, dan guru. Berdasarkan penelitian, diperoleh hasil bahwa perilaku bullying terjadi dalam bentuk bullying fisik dan bullying verbal. Bullying fisik berupa memukul, mendorong, memaksa, merusak, mencubit, menendang, menyenggol, menarik baju dan menjambak. Bullying verbal berupa membentak, menyoraki, berbicara kotor, mengejek dan memanggil dengan julukan tertentu.

Kata kunci: perilaku bullying, bentuk bullying, siswa

Social, Humanities, and Education Studies (SHEs): Conference Series https://jurnal.uns.ac.id/shes 


\section{PENDAHULUAN}

Sekolah merupakan lembaga pendidikan formal yang memiliki peran dan tanggung jawab penting dalam pembentukan karakter anak. Sekolah dasar sebagai pondasi utama keberlangsungan bagi pendidikan selanjutnya harus mampu mewujudkan pendidikan karakter maupun kepribadian bagi siswa. Pentingnya sekolah bagi siswa, maka sekolah seharusnya merupakan tempat yang aman, nyaman, dan menyenangkan. Namun sayangnya masih ada siswa yang merasa sekolah sebagai tempat yang tidak nyaman atau bahkan menjadi tempat yang menakutkan. Hal ini tentu bertentangan dengan UU. No 23 tahun 2002 pasal 54 tentang Perlindungan Anak yang menyatakan bahwa "Anak di dalam dan di lingkungan sekolah wajib dilindungi dari tindakan kekerasan yang dilakukan oleh guru, pengelola sekolah atau temantemannya di dalam sekolah yang bersangkutan, atau lembaga pendidikan lainnya". Oleh karena itu, sekolah harus benar-benar memperhatikan mengenai pendidikan karakter dan juga kepribadian. pendidikan harus dikelola dengan baik dan benar agar menghasilkan lulusan yang berkualitas guna menghadapi dunia dengan berbagai tantangan dan problematika serta dapat menghasilkan lulusan yang bermutu (Putri, 2018).

Seperti halnya di SDN Pandean Lamper 02 Kota Semarang, pendidikan karakter mulai terwujud dalam progam PPK (Penguatan Pendidikan Karakter). Namun, kegiatan tersebut tentu perlu ada tindakan nyata yang tidak hanya sebatas rutinitas kegiatan. Siswa perlu sekali diajarkan dan diberikan pemahaman mengenai perilaku dan karakter yang baik. Apalagi memandang saat ini, tindakan atau perilaku yang menyimpang sering kali terjadi di sekolah. Tidak hanya di sekolah menengah, di sekolah dasar pun hal tersebut sering terjadi. Tindakan menyimpang tersebut seringnya berupa tindak kekerasan, baik secara fisik maupun psikis.

Salah satu bentuk masalah atau gangguan terhadap perilaku yaitu kekerasan dan bullying. WHO global champaign for violence prevention menjelaskan bahwa 1,6 juta penduduk dunia kehilangan hidupnya karena tindak kekerasan dan terjadi 57000 kematian karena tindak kekerasan pada anak dibawah usia 15 tahun (Hamid, 2009).

Bentuk penyimpangan perilaku yang terjadi pada siswa SD tidak hanya berupa kekerasan yang merupakan salah satu bentuk dari perilaku agresif. Pada kenyataannya, hal-hal yang kita pandang sebagai perilaku yang wajar dilakukan anak usia SD terkadang tergolong dalam penyimpangan perilaku. Mulai dari sekedar mengejek temannya, memukul, mencubit, menjambak sampai menjegal temannya saat sedang berjalan.

Penyebab kekerasan yang terjadi tentu dipengaruhi oleh berbagai hal, seperti contohnya intimidasi terhadap pihak yang lebih lemah. Intimidasi yang dilakukan oleh pihak yang kuat terhadap pihak yang lemah inilah yang disebut bullying. Tindakan bullying adalah tindakan yang terus menerus terjadi sehingga mengakibatkan seseorang mengalami ketidaknyamanan. Bullying merupakan fenomena yang sudah ada didunia sejak tahun 1970 diawali di Skandinavia dan menurut Rudi (2010) mulai beberapa tahun terakhir menjadi perhatian peneliti, pendidik, organisasi perlindungan dan tokoh masyarakat.

Olweus dalam Geldard, (2012) menyatakan bahwa Bullying merupakan sebuah tindakan atau perilaku agresif yang disengaja, yang dilakukan oleh sekelompok orang atau seseorang secara berulang-ulang dan dari waktu ke waktu terhadap seorang korban yang tidak dapat mempertahankan dirinya dengan mudah. Menurut definisi tersebut, dapat didefinisikan bahwa dalam bullying ada pelaku dan juga korban.

Korban bullying biasanya merupakan anak baru di suatu lingkungan, anak termuda di sekolah, biasanya yang lebih kecil, tekadang ketakutan, mungkin tidak terlindung, anak yang pernah mengalami trauma atau pernah disakiti sebelumnya dan biasanya sangat peka, menghindari teman sebaya untuk menghindari kesakitan yang lebih parah, dan merasa sulit untuk meminta pertolongan (Coloroso, 2007). 
Begitu pula di SDN Pandean Lamper 02 Kota Semarang, yang mana ketika peneliti melakukan pengamatan langsung di lapangan banyak siswa yang melakukan tindakan bullying. Berdasarkan wawancara dengan kepala sekolah tindakan bullying yang terjadi seringnya dilakukan oleh teman yang sebaya, bahkan ada juga kakak kelas terhadap adik kelasnya. Tidak hanya itu, tindakan kekerasan juga dilakukan oleh siswa laki-laki terhadap siswa perempuan, siswa yang pendiampun menjadi korban dari siswa yang nakal. Tidak hanya itu, terkadang dengan gurupun siswa tidak takut dan melakukan tindakan atau perilaku yang kurang baik.

Kasus bullying yang kerap terjadi dalam dunia pendidikan di Indonesia kian memprihatinkan. Hasil kajian Konsorsium Nasional Pengembangan Sekolah Karakter tahun 2014 menyebutkan, hampir setiap sekolah di Indonesia ada kasus bullying, meski hanya bullying verbal dan psikologis/mental. Contoh kasus yang terjadi pada Februari 2019, seorang anak SD kelas 2 di Sydney, Australia menulis pesan bunuh diri kepada gurunya karena tidak tahan terus menerus menjadi korban bullying. Seminggu sebelum insiden, pesan bunuh diri itu ditinggalkan di atas meja gurunya. Jack mengaku dipukuli oleh teman-teman sekelas selama 10 menit. Contoh lainnya terjadi di Sukabumi pada tahun 2017, SR (8), seorang siswa kelas II SDN Longkewang, Desa Hegarmanah, Kecamatan Cicantayan, Kabupaten Sukabumi, Jawa Barat, meregang nyawa, dimana SR tewas diduga setelah berkelahi dengan rekan di sekolahnya.

Kasus lain juga ditemukan di Kota Semarang, berdasarkan observasi dan wawancara dilakukan oleh peneliti pada tanggal 23 Agustus 2019 di SDN Pandean Lamper 02 Kota Semarang, ditemukan beberapa penyimpangan perilaku yang dilakukan oleh siswa. Siswa melakukan perilaku bullying terhadap temannya seperti menjambak, mencubit, memukul, menendang, mendorong, dan menjegal, berkata kotor, mengejek, dan memaki.

Kasus-kasus di atas tentu membawa kepada penjelasan bahwa masyarakat khusunya harus lebih paham mengenai bullying. Apa penyebab munculnya tindakan bullying, apa dampak bagi pelaku, korban, dan saksi, bagaimana bentuk-bentuk tindakan bullying, dan bagaimana cara mencegah dan memberhentikan tindakan bullying ini.

Bullying menjadi salah satu kasus yang sering terjadi di sekolah. Namun kasus ini masih kurang mendapat perhatian karena seringkali dianggap sebagai hal yang biasa terjadi di sekolah. Di Indonesia sudah banyak korban bullying yang tidak disadari oleh si pelaku, korban bullying hanya bisa diam, pasrah dan tidak dapat melawan. Bullying atau aksi perundungan seperti fenomena gunung es. Kejadian itu sudah banyak terjadi, namun terkadang masyarakat abai dengan fenomena tersebut.

Padahal seharusnya, guru sebagai pendidik harus mengembangkan potensi dasar peserta didik secara optimal sehingga menciptakan suasana pembelajaran yang kondusif untuk proses belajar mengajar yang aman dan nyaman, membimbing peserta didik agar dapat menciptakan hubungan yang baik, menghindari perselisihan serta konflik di dunia pendidikan.

Melihat permasalahan yang begitu luas terkait dengan tindakan bullying ini, peneliti melakukan penelitian mengenai bentuk-bentuk tindakan bullying dan bagaimana penyebab yang menimbulkan tindakan bullying khususnya di SDN Pandean Lamper 02 Kota Semarang.

\section{METODE}

Jenis penelitian ini adalah kualitatif dengan menggunakan pendekatan deskriptif kualitatif. Tempat penelitian ini dilaksanakan di SDN Pandean Lamper 02 Kota Semarang. Subjek penelitian ini adalah siswa yang terindikasi sebagai pelaku atau korban bullying, kepala sekolah, dan guru. Teknik pengumpulan data yang digunakan dalam penelitian ini yaitu observasi, wawancara dan dokumentasi dan gabungan ketiganya (triangulasi). Pertanyaan yang diberikan ke responden adalah pertanyaan 
terbuka. Teknik analisis data dalam penelitian ini adalah teknik analisis interaktif, yaitu data reduction, data display dan conclusion drawing/verification.

\section{HASIL DAN PEMBAHASAN}

Berikut ini dipaparkan hasil penelitian dari data yang diperoleh peneliti terkait dengan bullying yang terjadi di SDN Pandean Lamper 02 Kota Semarang. Bagian pertama akan dipaparkan mengenai bentuk-bentuk bullying dan faktor yang menyebabkan terjadinya bullying dan bagian kedua adalah analisis pembahasan terhadap temuan peneliti.

\section{a. Bentuk-bentuk Bullying}

Coloroso (2007) mengelompokkan bullying dalam beberapa bentuk yaitu: pertama, bullying secara verbal yaitu berupa pemberian julukan nama, celaan, fitnah, kritikan kejam, penghinaan, pernyataan-pernyataan yang bernuansa ajakan seksual atau pelecehan seksual, terror, surat-surat yang mengintimidasi, tuduhan-tuduhan yang tidak benar kasak-kusuk yang keji dan keliru, gosip dan sebagainya. Kedua, bullying secara fisik berupa memukuli, menendang, menampar, mencekik, menggigit, mencakar, meludahi, dan merusak serta menghancurkan barang-barang milik anak yang tertindas. Ketiga, bullying secara relasional pelemahan harga diri korban secara sistematis melalui pengabaian, pengucilan atau penghindaran. Keempat, bullying secara elektronik yaitu Bullying elektronik merupakan bentuk perilaku bullying yang dilakukan pelakunya melalui sarana elektronik seperti komputer, handphone, internet, website, chatting, e-mail, SMS dan sebagainya.

Temuan di lapangan berdasarkan hasil observasi menunjukan bahwa bentukbentuk bullying yang muncul di SDN Pandean Lamper 02 Semarang terjadi dalam bentuk bullying fisik dan bullying verbal. Bullying fisik, berupa memukul, mendorong, memaksa, merusak, mencubit, menendang, menyenggol, menarik baju dan menjambak. Sedangkan, bullying verbal berupa membentak, menyoraki, berbicara kotor, mengejek dan memanggil dengan julukan tertentu.

Hal diatas diperkuat berdasarkan hasil wawancara dengan guru, yang menyatakan bahwa perilaku bullying yang kerap terjadi di sekolah adalah bullying fisik dan bullying verbal. Bullying fisik terjadi dalam bentuk memukul, menjambak, menjotos, menendang, mencubit dan memaksa. Sedangkan bullying verbal terjadi dalam bentuk membentak, berbicara kasar, mengejek, mengolok-olok, dan menyoraki.

Selain itu, ketika peneliti melakukan wawancara dengan siswa yang peneliti amati sebelumnya terindikasi sebagai pelaku bullying menyatakan bahwa siswa tersebut sering melakukan tindakan bullying terhadap temannya. Baik dalam bentuk bullying fisik maupun verbal. Begitu pula dengan korban bullying yang menyatakan bahwa siswa tersebut sering mendapatkan perilaku yang tidak menyenangkan dari teman-temannya. Bentuk perilaku tersebut yakni sering didorong, dijambak, sampai dipukul. Pernah juga seringkali diejek dan diolok-olok.

Hal di atas sejalan dengan yang diungkapkan oleh Sejiwa (Gerald 2012), terdapat 3 bentuk bullying, yaitu bullying fisik, bullying verbal, dan bullying mental. Bullying fisik adalah bullying yang sasarannya adalah menyakiti fisik seseorang, contohnya menampar, menendang, dan memukul. Bullying verbal adalah bullying yang dilakukan dengan verbal, contohnya menghina, memaki, dan melecehkan. Bullying mental adalah bullying yang menyakiti mental korbannya, contohnya mengancam, mempermalukan, dan mengejek.

Sebagaimana yang diungkapkan oleh (Astuti, 2008) bahwa bullying merupakan bagian dari tindakan agresif yang dilakukan berulangkali oleh seseorang/ anak yang memiliki kekuatan lebih terhadap anak yang lemah baik secara fisik maupun psikologis. 
Berdasarkan temuan peneliti tersebut di atas, dapat dianalisis bahwa bentuk perilaku bullying yang terjadi di SDN Pandean Lamper 02 Kota Semarang adalah dalam bentuk bullying fisik dan bullying verbal.

\section{b. Faktor Penyebab Terjadinya Bullying}

Faktor penyebab bullying pada kasus yang terjadi di SDN Pandean Lamper 02 Kota Semarang dipengaruhi oleh berbagai hal. Kondisi pelaku maupun korban, lingkungan keluarga, dan kondisi psikologis subjek merupakan beberapa penyebab terjadinya perilaku bullying.

Berdasarkan analisis hasil wawancara dengan guru mengatakan bahwa "siswa yang melakukan bullying di SDN Pandean Lamper 02 Kota Semarang memiliki keluarga yang bermasalah". Selain itu, beliau juga mengungkapkan bahwa siswa pelaku bullying adalah siswa yang memiliki masalah perilaku dalam kesehariannya.

Hasil wawancara dengan siswa yang terindikasi sebagai pelaku juga menyatakan hal yang sama, selain karena faktor keluarga juga karena faktor emosi. Siswa tersebut mengungkapkan bahwa ketika dia melakukan tindakan bullying seringkali disebabkan karena temannya juga melakukan hal yang sama, sehingga dia membalasnya dengan hal yang sama bahkan lebih. Selain itu, emosi yang tidak terkontrol juga menyebabkan dia sering melakukan bullying terutama pada siswa yang lemah.

$\mathrm{Hal}$ di atas diperkuat dengan hasil observasi yang peneliti peroleh, bahwa penyebab terjadinya bullying salah satunya karena siswa tidak dapat menahan emosinya. Misalnya saja ketika pembelajaran berlangsung, para siswa berebut untuk maju ke depan kelas, karena tidak ada yang mengalah pada akhirnya siswa yang lemah berujung pada mendapatkan bullying seperti didorong, dijambak, sampai dengan dikata-katai.

Faktor kepribadian dan kondisi perilaku serta lingkungan individu saling berkaitan dan saling berpengaruh sehingga muncullah perilaku bullying pada siswa. Pelaku bullying ingin menunjukkan kekuasaannya, marah karena korban tidak berperilaku sesuai dengan yang diinginkan, serta pelaku mendapatkan kepuasan setelah melakukan aksi bullying.

Hal tersebut di atas didukung oleh Astuti, (2008) yang menyatakan faktor- faktor yang memicu terjadi bullying antara lain adalah: perbedaan kelas (senioritas), ekonomi, agama, gender; tradisi senioritas; keluarga yang tidak rukun; situasi sekolah yang tidak harmonis atau diskriminatif; karakter individu/ kelompok seperti: dendam/iri hati, adanya semangat ingin menguasai korban dengan kekuatan fisik, meningkatkan popularitas pelaku dikalangan teman sepermainannya; persepsi nilai yang salah atas perilaku korban.

Sejalan dengan Astuti, hasil penelitian Wiyani (2012) dalam fenomena bullying yang dialami anak di rumah dan di sekolah, menunjukan bahwa anak-anak dibawah umur 12 tahun sangat rawan akan tindakan kekerasan oleh orang tua maupun guru. Perilaku bullying cenderung memunculkan perilaku agresif dan saat ini lebih banyak mendominasi di dunia pendidikan. Sama halnya dengan hasil penelitian dari Rahmadara (2012) menjelaskan bahwa keluarga, sekolah, kepribadian, serta emosi, secara bersamaan dapat menjadi pemicu untuk tingkah laku bullying. Disamping itu, faktor lain yang menyebabkan bullying atau agresi adalah bentuk tertentu dari pengasuhan dan masalah keluarga (Sullivan, 2005 \& Rahmadara, 2012).

Dengan demikian dapat disimpulkan bahwa penyebab terjadinya bullying antara lain disebabkan oleh kondisi psikologis pelaku yang mudah marah dan mudah tersulut emosi, pernah mendapatkan perilaku yang kurang baik dalam lingkungan keluarganya, serta kondisi sosial pelaku. 


\section{SIMPULAN}

Kesimpulan hasil penelitian ini adalah sebagai berikut:

1. Bentuk bullying yang terjadi di SDN Pandean Lamper 02 Kota Semarang yakni bullying fisik dan bullying verbal. Bullying fisik berupa memukul, mendorong, memaksa, merusak, mencubit, menendang, menyenggol, menarik baju dan menjambak. Bullying verbal berupa membentak, menyoraki, berbicara kotor, mengejek dan memanggil dengan julukan tertentu.

2. Faktor penyebab terjadinya bullying disebabkan oleh kondisi psikologis, emosional, lingkungan keluarga, dan kondisi status sosial.

\section{DAFTAR PUSTAKA}

Astuti, P. R. (2008). Meredam Bullying: 3 cara efektif mengatasai kekerasan pada anak. Jakarta: Grasindo.

Coloroso, Barbara. (2007). Stop Bullying: Memutus Rantai Kekerasan Anak dari Prasekolah hingga SMU. Diterjemahkan oleh: Santi Indra Astuti. Jakarta: PT. Serambi Ilmu Semesta.

Geldard, Kathryn. (2012). Konseling Remaja: Intervensi Praktis Bagi Remaja Berisiko. Yogyakarta: Pustaka Pelajar.

Hamid, A.Y. (2009). Bunga rampai asuhan keperawatan kesehatan jiwa. Jakarta: EGC

Muhammad Fahrur Safi'i. (2019). Selain Audrey, 4 Kasus Bullying Anak Sekolah Ini Juga Bikin Miris. Liputan6. Diakses dari https://hot.liputan6.com/read/3938088/selain-audrey-4-kasus-bullying-anaksekolah-ini-juga-bikin-miris.

Rahmadara, B. (2012). Hubungan antara polaasuh orang tua dan peran-peran dalam perilaku bullying pada siswa sekolah Dasar. (Skripsi tidak dipublikasikan). Fakultas Psikologi Universitas Indonesia, Depok.

Rudi, T. (2010). Informasi perihal bullying. 8 Januari 2013. bigloveadagio. files.wordpress.com/.../ informasi_perihal_bullying.pdf

Sullivan, K., Cleary, M., \& Sullivan, G. (2005). Bullying in Secondary Schools. California: Corwin Press Inc.

Undang-undang No 23 tahun 2002. Tentang Perlindungan Anak. Jakarta: Visimedia.

Wiyani, N. A. (2012). Save Our Children from School Bullying. Jogjakarta: Ar-Ruzz Media. 